Article

\title{
Characterization of Date Palm Fiber-Reinforced Different Polypropylene Matrices
}

\author{
Mohammed Sh. Al-Otaibi ${ }^{1}$, Othman Y. Alothman ${ }^{2, *} \mathbb{D}^{\mathbb{C}}$, Maher M. Alrashed ${ }^{2}$, Arfat Anis ${ }^{3}(\mathbb{D}$, \\ Jesuarockiam Naveen ${ }^{4}$ and Mohammad Jawaid ${ }^{5, * \mathbb{D}}$ \\ 1 National Industrialization Company (Tasnee), Riyadh 11496, Saudi Arabia; moham.alotaibi@tasnee.com \\ 2 Department of Chemical Engineering, College of Engineering, King Saud University, Riyadh 11421, \\ Saudi Arabia; mhalrashed@ksu.edu.sa \\ 3 SABIC Polymer Research Center, Department of Chemical Engineering, College of Engineering, King Saud \\ University, Riyadh 11421, Saudi Arabia; aarfat@ksu.edu.sa \\ 4 Department of Mechanical and Manufacturing Engineering, Faculty of Engineering, Universiti Putra \\ Malaysia, Serdang 43400, Selangor, Malaysia; gandhi.naveen66@gmail.com \\ 5 Laboratory of Biocomposite Technology, Institute of Tropical Forestry and Forest Products (INTROP), \\ Universiti Putra Malaysia, Serdang 43400, Selangor, Malaysia \\ * $\quad$ Correspondence: othman@ksu.edu.sa (O.Y.A.); jawaid@upm.edu.my (M.J.); Tel.: +603-8946-6960 (M.J.)
}

Received: 7 December 2019; Accepted: 26 February 2020; Published: 5 March 2020

\begin{abstract}
In this study, the effect of different polypropylene (PP) matrices (homopolymer (HPP), impact copolymer (ICP), and recycled polypropylene (rPP)) on the mechanical, morphological, and thermal properties of date palm fiber (DPF)-reinforced PP composites was investigated. The DPFs were treated with an alkali solution, and composites were fabricated with different DPF loadings $(5,10$, and $15 \mathrm{wt} \%)$ and lengths (less than $2 \mathrm{~mm}$ and 8-12 $\mathrm{mm}$ ). It was found that the tensile properties of the DPF/ICP and DPF/rPP composites were similar to those of the DPF/HPP composites. The addition of fiber to the matrix reduced its tensile strength but increased the modulus. The alkali treatment improved the compatibility between the fibers and the matrix by removing hemicellulose and other impurities. Fourier transform infrared spectroscopy confirmed hemicellulose removal. The morphology of the alkali-treated fractured tensile specimen revealed improved adhesion and less fiber pull out. Differential scanning calorimetry revealed that the alkali treatment enhanced the crystallinity index. Thermogravimetric analysis showed that the addition of DPFs into the PP matrix reduced the thermal stability of the composite. However, the thermal stability of the treated fiber-reinforced rPP and ICP composites was similar to that of the DPF/HPP composite. Hence, rPP can be used as an alternative to HPP with DPFs.
\end{abstract}

Keywords: date palm fiber; homopolymer polypropylene; copolymer polypropylene; recycled polypropylene; alkali treatment

\section{Introduction}

The utilization of natural resources for industrial applications will enhance the biodegradability of many daily-life disposable products, besides producing new materials with better mechanical, physical, and thermal properties [1]. Although natural fiber-based polymeric composites have existed since 1900, they did not gain much attention until the 1980s. However, nowadays, natural or green composites are extensively utilized owing to eco-legislation, and the benefits of natural fiber-reinforced composites, such as a high strength, modulus, and strength-to-weight ratio, as well as cost-effectiveness and biodegradability [2].

Date palm fibers (DPFs) are abundant in Arab countries, with approximately two-thirds of the date palm trees in the world existing in Arab lands. The date palm is considered the most important 
palm species after coconut and oil palms [3]. During cultivation and fruit harvesting, date palm trees produce different residues, such as bunch stalks, leaf stalks, and tree trunks. These huge bio-wastes from the date palm trees may pollute the environment [4]. These agro-wastes can be utilized to produce low-cost sustainable and eco-friendly materials [5]. In particular, these agro-wastes can be potential reinforcements for thermoset or thermoplastic polymers for non-load-bearing applications.

Polypropylene is a thermoplastic polymer produced by the polymerization of propylene monomer in the presence of a catalyst under heat and pressure. Propylene (propene) is an unsaturated hydrocarbon containing only carbon and hydrogen. A homopolymer is a polymer that is formed by the polymerization of a single monomer and contains only one kind of repeating unit throughout the polymeric chain [6]. Homo-polypropylene offers a high strength, stiffness, and strength-to-weight ratio compared with its copolymer. In addition, it possesses good chemical resistance and weldability, which render it applicable in several corrosion-resistant structures. Copolymers, also known as heteropolymers, consist of two or more different monomers. The process of joining two monomers is called copolymerization, and the main purpose of this process is to modify the properties of manufactured plastics to meet specific market needs. Polypropylene impact copolymers (ICPs) are produced by the copolymerization of propylene and ethylene monomers in the presence of a catalyst (phthalate-free Ziegler-Natta catalyst). ICPs are used in thermoforming, injection molding, and blow molding. Plastic recycling is a process used to recover plastic scraps for reprocessing and using them to produce valuable products. Polypropylene recycling is one of the most common plastic recycling processes, which mainly includes sorting, collecting, cleaning, and reprocessing of polypropylene wastes [6].

Abu-Sharkh et al. [7] investigated the effect of adding a compatibilizer on the mechanical performance of DPF/polypropylene composites. Initially, the DPF and the polymer were compounded at $200{ }^{\circ} \mathrm{C}$ using an extruder. Subsequently, the composite specimens for mechanical testing were injection molded as per the standard dimensions. The mechanical test results showed that the incorporation of a compatibilizer (Epolene E-43) enhanced the mechanical properties. Alawar et al. [8] investigated the effect of $\mathrm{NaOH}$ (concentrations: $0.5 \%, 1 \%, 1.5 \%, 2.5 \%$, and $5 \%$ ) and hydrochloric acid $(0.3,0.9$, and $1.6 \mathrm{~N})$ treatments on the mechanical and thermal performances of DPFs for composite reinforcement. The treatments were carried out for $1 \mathrm{~h}$ at $100^{\circ} \mathrm{C}$. The mechanical test results revealed that the fibers treated with $1 \% \mathrm{NaOH}$ had higher strength and modulus. In addition, the thermal stability improved after the alkali treatment. However, an opposite trend was observed in the case of hydrochloric acid treatment, where no such improvements were observed. Abdal-hay et al. [9] investigated the effects of varying DPF diameter (800-600, 600-400, and 400-200 $\mu \mathrm{m}$ ) and alkali treatment on the properties of DPFs and its composites. They reported that the DPFs with smaller diameters exhibited higher mechanical properties compared with the coarse fibers. The alkali-treated fiber and composites exhibited an enhanced load-carrying capacity, and consequently, the treated fibers and their composites exhibited higher strength and modulus compared with those of the untreated fibers and their composites. The Fourier transform infrared (FTIR) analysis confirmed that the carbonyl group $(\mathrm{C}=\mathrm{O})$ stretching vibration at $\sim 1728 \mathrm{~cm}^{-1}$ originating from hemicellulose disappeared due to the alkali treatment.

Nowadays, due to eco-legislation and environmental pollution, many researchers have focused on reducing the utilization of polymeric materials and products. This goal has motivated the researchers to identify promising natural materials which are eco-friendly and cost effective. The purpose of this research is effective utilization of recycled polypropylene in order to reduce the consumption of homopolymer. Hence, this study focuses on evaluating the effects of different polypropylene (PP) matrices (homopolymer (HPP), impact copolymer (ICP), and recycled polypropylene (rPP)) on the mechanical, thermal, and morphological properties of DPF-reinforced polypropylene composites. Moreover, the properties were improved using alkali treatments. Furthermore, this research has proven that rPP can be used as an alternative to HPP with DPFs. 


\section{Materials and Methods}

\subsection{Materials}

Table 1 shows the polymers used in this research and their properties. A commercial homopolymer polypropylene (HPP; melt flow index (MFI): $12 \mathrm{~g} / 10 \mathrm{~min}$ ) was supplied by TASNEE (Riyadh, Saudi Arabia) and an impact copolymer polypropylene (ICP; MFI: $70 \mathrm{~g} / 10 \mathrm{~min}$ ) was supplied by SABIC (Riyadh, Saudi Arabia). The above-mentioned HPP was used as a matrix in the DPF-based polymeric composites. In addition, recycled homopolymer polypropylene (rPP) was used to investigate the feasibility of using recycled plastics with natural resources. Composite samples were prepared with different polymer loadings. Exxelor supplied by ExxonMobil (Machelen, Belgium) was used as a coupling agent $(3 \%)$ in the composite formulations to enhance the compatibility between the fibers and the PP matrix.

Table 1. Polymers used with melt index, density, and co-monomer types.

\begin{tabular}{|c|c|c|c|}
\hline Polymer & Type & $\begin{array}{l}\text { Melt Index (g/10 min } @ \\
\left.230^{\circ} \mathrm{C}, 2.16 \mathrm{~kg}\right)\end{array}$ & Density $\left(\mathrm{kg} / \mathrm{m}^{3}\right)$ \\
\hline TASNEE PP & Homopolymer (HPP) & 12 & 900 \\
\hline Industrial Recycle of TASNEE PP & Homopolymer (rPP) & 12 & 900 \\
\hline SABIC PP & Copolymer (ICP) & 70 & 905 \\
\hline
\end{tabular}

DPFs supplied by the Al-Nojoom Factory (Al-Kharj, Saudi Arabia) were used as a filler in the compounding process to prepare the composite samples. For comparison, DPFs of different sizes were used in this work. The raw fibers were milled into two different sizes: powders of less than $2 \mathrm{~mm}(\mathrm{P})$ and fibers of $8-12 \mathrm{~mm}$ length (F). The DPFs were treated with a $5 \% \mathrm{NaOH}$ aqueous solution at room temperature for $24 \mathrm{~h}$. Subsequently, the fibers were cleaned with water to remove excess $\mathrm{NaOH}$ and heat treated at $70{ }^{\circ} \mathrm{C}$ for $72 \mathrm{~h}$.

\subsection{Fabrication of Date Palm Fiber/Polypropylene Composites}

Table 2 shows the formulations of different composite samples. The DPF content in the PP/DPF composite was varied as 5,10 , and $15 \mathrm{wt} \%$. The compounding process was performed using a twin-screw extruder (Xplore MC 15 micro-compounder Sittard, The Netherlands). The residence time in the extruder was $1 \mathrm{~min}$ for each sample and the screw speed was $100 \mathrm{rpm}$. Tensile test specimens were prepared using an Xplore micro-injection molding machine.

Table 2. Formulations of composite samples.

\begin{tabular}{cccc}
\hline Sample Designation & \multicolumn{3}{c}{ Fiber Loading $\%$} \\
\hline HNTP & 5 & 10 & 15 \\
HNTF & 5 & 10 & 15 \\
HTP & 5 & 10 & 15 \\
HTF & 5 & 10 & 15 \\
RTP & 5 & 10 & 15 \\
RTF & 5 & 10 & 15 \\
CTP & 5 & 10 & 15 \\
CTF & 5 & 10 & 15 \\
\hline
\end{tabular}

Matrix: $\mathrm{H}=$ homo polypropylene, $\mathrm{R}=$ recycled polypropylene, $\mathrm{C}=$ impact copolymer. Date palm fiber size: $\mathrm{P}$ $=$ powder, $\mathrm{F}=$ fiber. Treatment: $\mathrm{T}=$ treated, $\mathrm{NT}=$ untreated. Example: $\mathrm{HNTF}=$ homo-PP with untreated date palm fiber. 


\subsection{Characterization}

\subsubsection{Tensile Test}

Tensile testing was carried out as per ASTM D638 with a Zwick/Roell Z010 instrument using dog-bone-shaped composite samples [10]. The crosshead speed was maintained at $5 \mathrm{~mm} / \mathrm{min}$.

\subsubsection{Differential Scanning Calorimetry (DSC)}

The thermal properties of DPF/polypropylene composites were investigated by differential scanning calorimetry (TA Instruments, Model DSC-Q200, Malvern, UK). Approximately 5-7 mg of a powdered DPF/PP composite sample was loaded in an aluminum pan, while an empty aluminum pan was used as a reference. DSC was performed in a nitrogen environment from 50 to $195^{\circ} \mathrm{C}\left(10^{\circ} \mathrm{C} / \mathrm{min}\right)$. The $\%$ crystallinity can be determined using the following relation:

$$
\% \text { Crystallinity }=(\Delta \mathrm{Hm}-\Delta \mathrm{Hrc}) /(\mathrm{x} \Delta \mathrm{Hf}),
$$

where $\Delta \mathrm{Hm}$ and $\Delta \mathrm{Hrc}$ are the melting enthalpy and secondary crystallization enthalpy during the DSC heating process, respectively; $\triangle \mathrm{Hf}$ is the melting enthalpy of $100 \%$ crystallized PP ( $\triangle \mathrm{Hf}$ for HPP, $\mathrm{rPP}$, and ICP is $207 \mathrm{~J} / \mathrm{g}$ (taken from supplier data sheet)); and $\mathrm{x}$ is the content of the PP in composite.

\subsubsection{Thermogravimetric Analysis (TGA)}

The weight loss and thermal stability of the DPF/PP composites were analyzed using a thermogravimetric analyzer as per ASTM E1131-03. Powdered samples of around $20 \mathrm{mg}$ were kept in an alumina crucible and subjected to pyrolysis in $\mathrm{N}_{2}$ atmosphere $\left(50 \mathrm{~mL} \mathrm{~min}{ }^{-1}\right)$. The analysis was performed in the temperature range of $30-900^{\circ} \mathrm{C}$ at a heating rate of $10^{\circ} \mathrm{C} / \mathrm{min}$.

\subsubsection{Morphological Analysis}

The microstructure and morphology of the DPF/PP composites were investigated using a scanning electron microscope (FEI Quanta 200) at $20 \mathrm{kV}$. The fractured samples were sputter-coated with gold to visualize the failure modes effectively.

\subsubsection{Attenuated Total Reflectance (ATR)-FTIR Analysis}

ATR is a widely used FTIR spectroscopy sampling tool. The change in the functional groups after chemical treatment was investigated by ATR-FTIR analysis.

\section{Results}

\subsection{Tensile Properties}

Figure 1 shows that the tensile strength has declined after DPF (15\%) addition in all composite samples. However, the percentage drop in tensile strength varies with respect to the type of matrix. In addition, it has been found that the alkali treatment of the DPFs mitigated the tensile strength reduction. The overall tensile strength reduction is due to the poor interfacial interaction between the hydrophilic DPFs and the hydrophobic polymer matrices [11]. On the other hand, the alkali treatment enhanced the adhesion between the DPFs and polymeric matrices by removing hemicelluloses and other impurities. In addition, it cleared the micro-pores in the fibers [12].

Figure 2 presents the tensile moduli of different DPF/PP composites. The tensile moduli of all the composites increased, especially the treated fibers. Both the HTP and HTF composites exhibited higher moduli among the composites. Nonetheless no significant difference was observed between the tensile properties, as shown in Figures 1 and 2, of the treated DPF/rPP and DPF/HPP composites. 


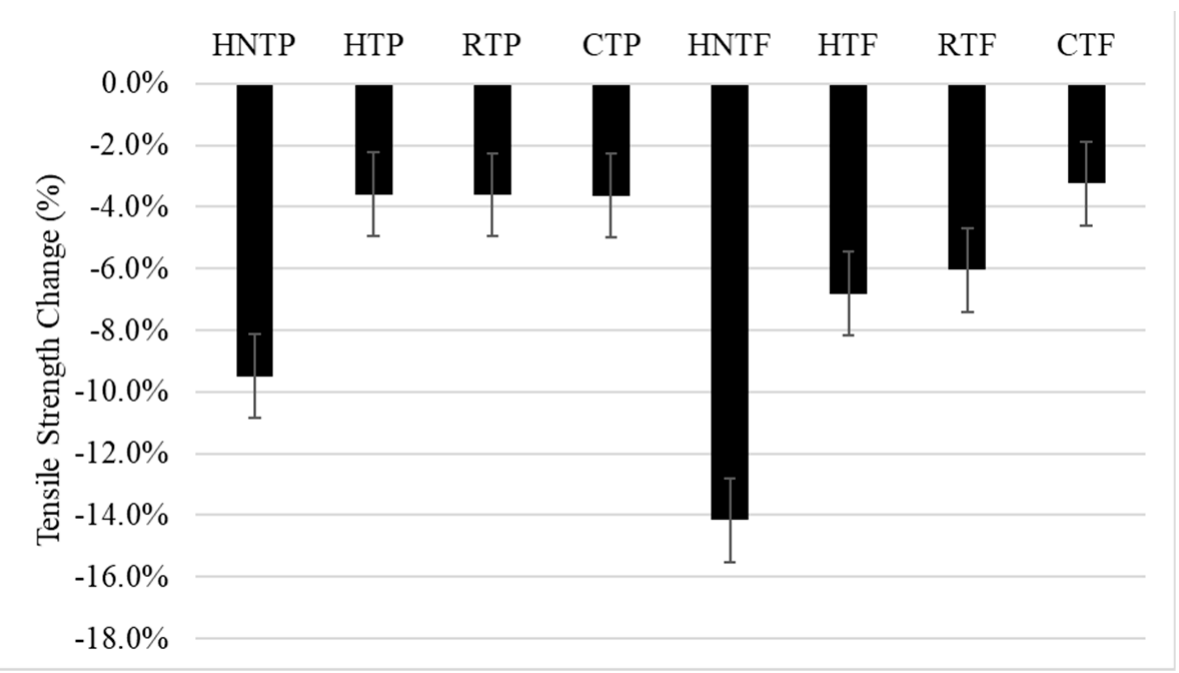

Figure 1. Change in tensile strength.

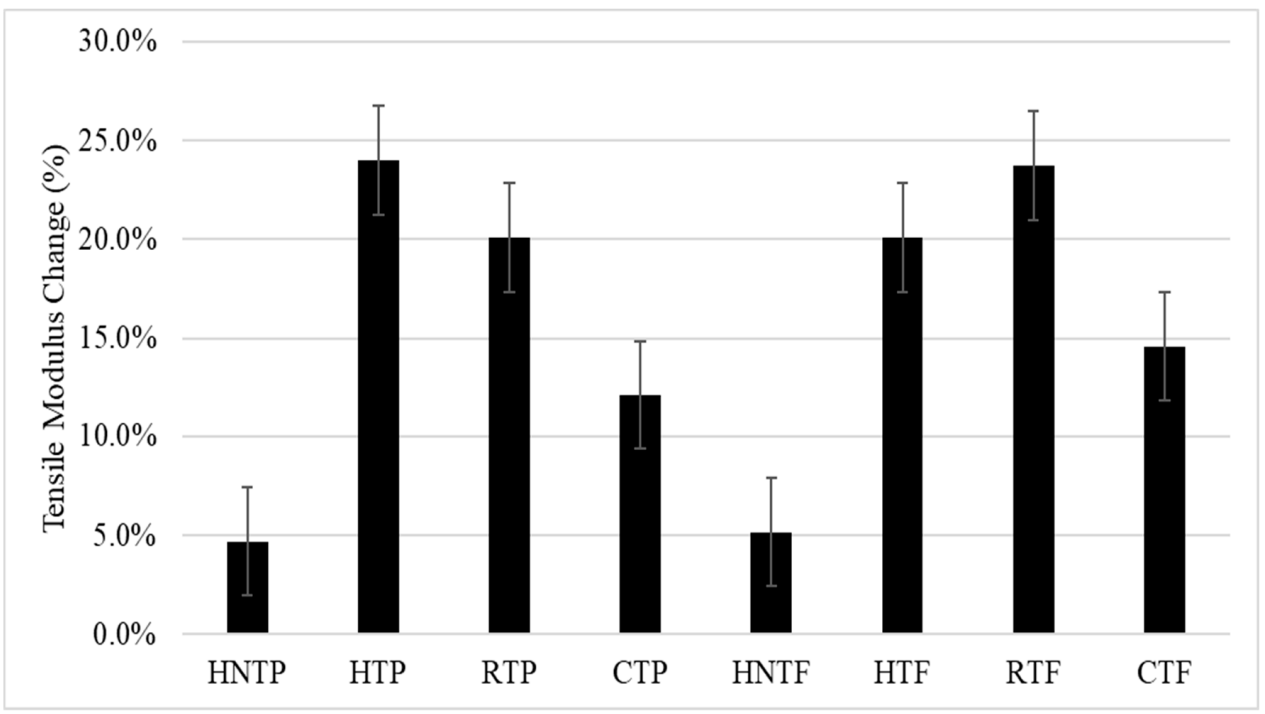

Figure 2. Change in tensile modulus.

\subsubsection{Effect of DPF Loading and Treatment on Tensile Properties}

Figure 3 displays the variation in tensile strength with fiber loading. The tensile strength decreased with an increase in fiber content, which is mainly due to the incompatibility or poor interfacial interaction between the hydrophobic polymer and the hydrophilic fiber.

Figure 3 shows the mechanical performances of the PP/raw fiber (untreated) composite and PP/alkali-treated fiber composite as a function of fiber loading. As can be seen, for both the fiber sizes and at all fiber loadings, the treated fiber performed better than the untreated fiber. Alkali treatment enhanced the interfacial adhesion between the fiber and polypropylene matrix [13,14].

Figure 4 shows the tensile modulus at various fiber loadings. As can be seen, the tensile modulus increased with an increase in fiber loading from $5 \%$ to $15 \%$, which is consistent with the findings of Abu Sharkh et al. [7] who reported an increasing trend up to $30 \%$ loading. 


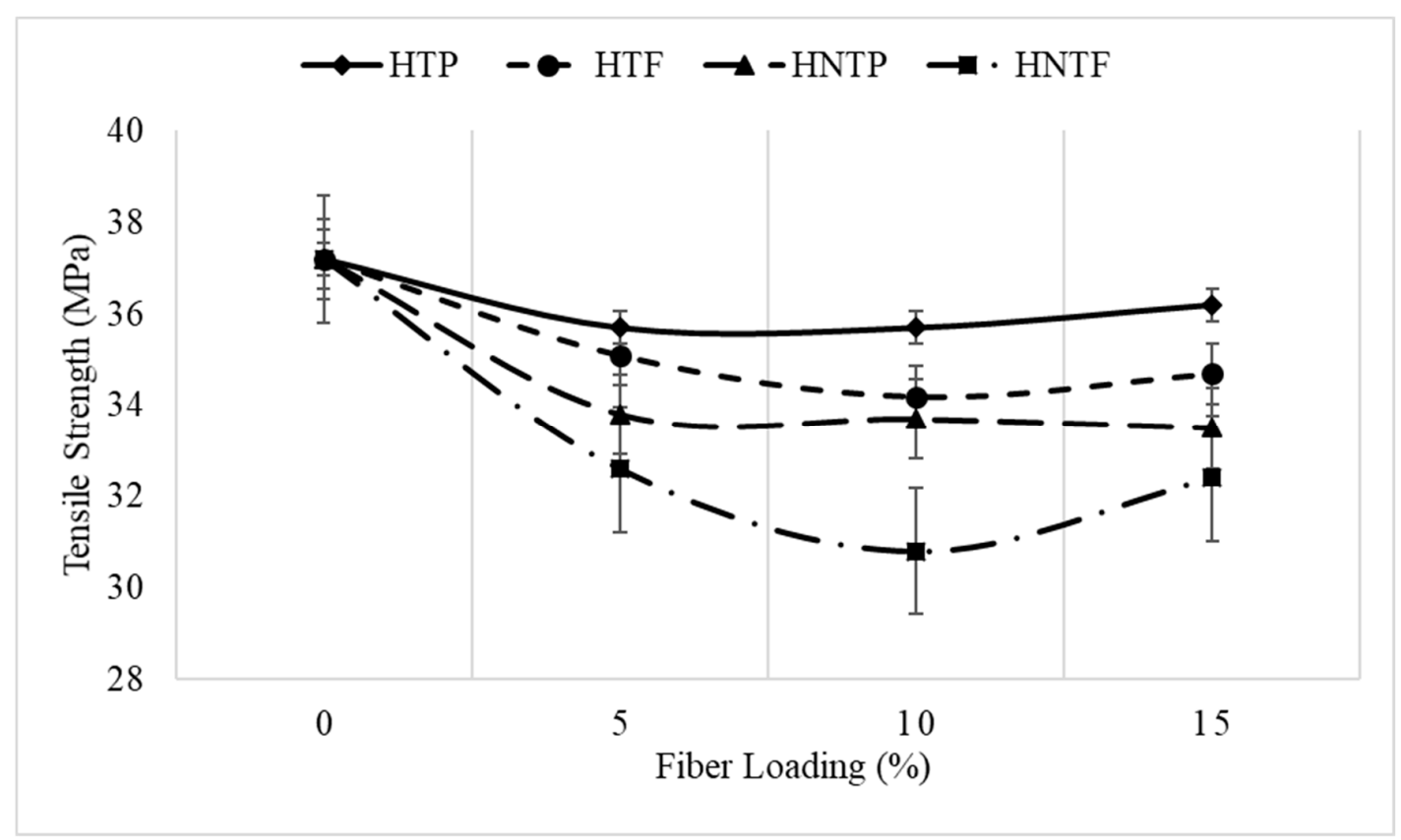

Figure 3. Effect of treatment and fiber loading on tensile strength.

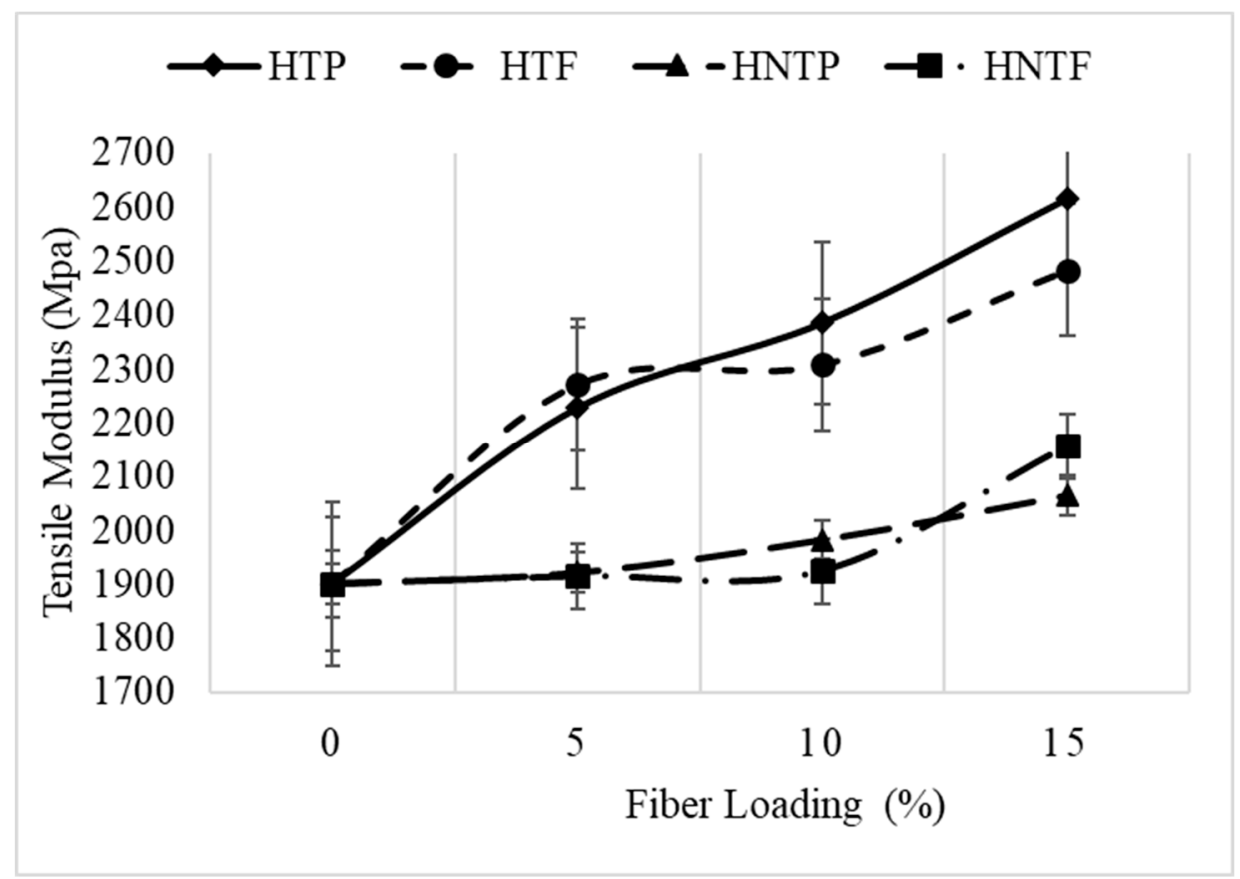

Figure 4. Effect of treatment and fiber loading on tensile modulus.

\subsubsection{Effect of Fiber Loading and Matrix Type on Tensile Properties}

Figure 5 shows the tensile strength at different fiber loadings and for different matrices (HPP and $\mathrm{rPP}$ ). As can be seen, the tensile strength decreased with an increase in fiber loading for both the fiber sizes. Moreover, rPP exhibited a similar trend as that of HPP. 


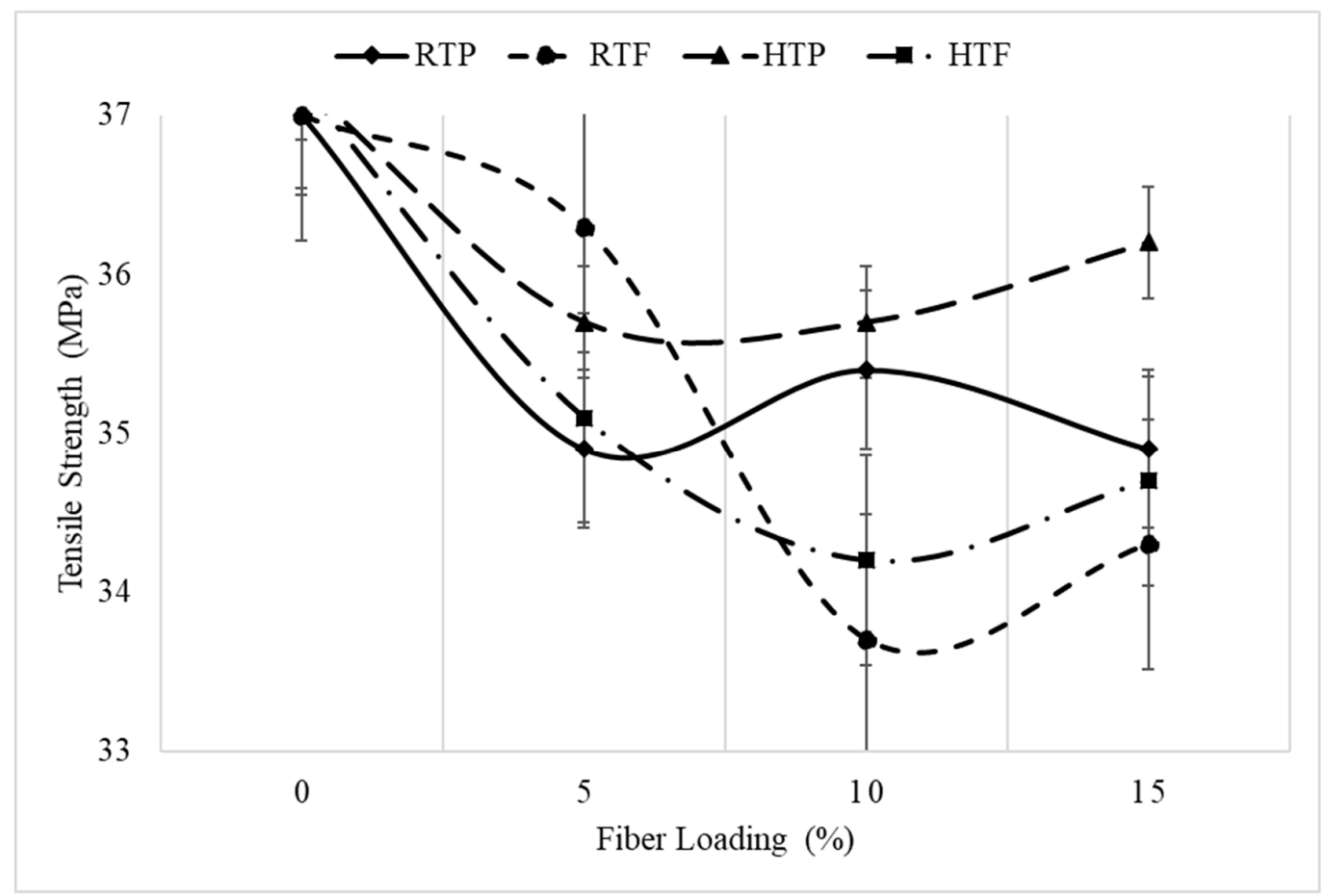

Figure 5. Tensile strengths of virgin and recycled polypropylene (PP) composites.

Figure 6 shows the tensile modulus for various fiber loadings. The tensile modulus increased with an increase in fiber content for both the virgin and recycled PP matrices, and both of them exhibit the same trend, which proves that the tensile modulus is unaffected by the recycling process.

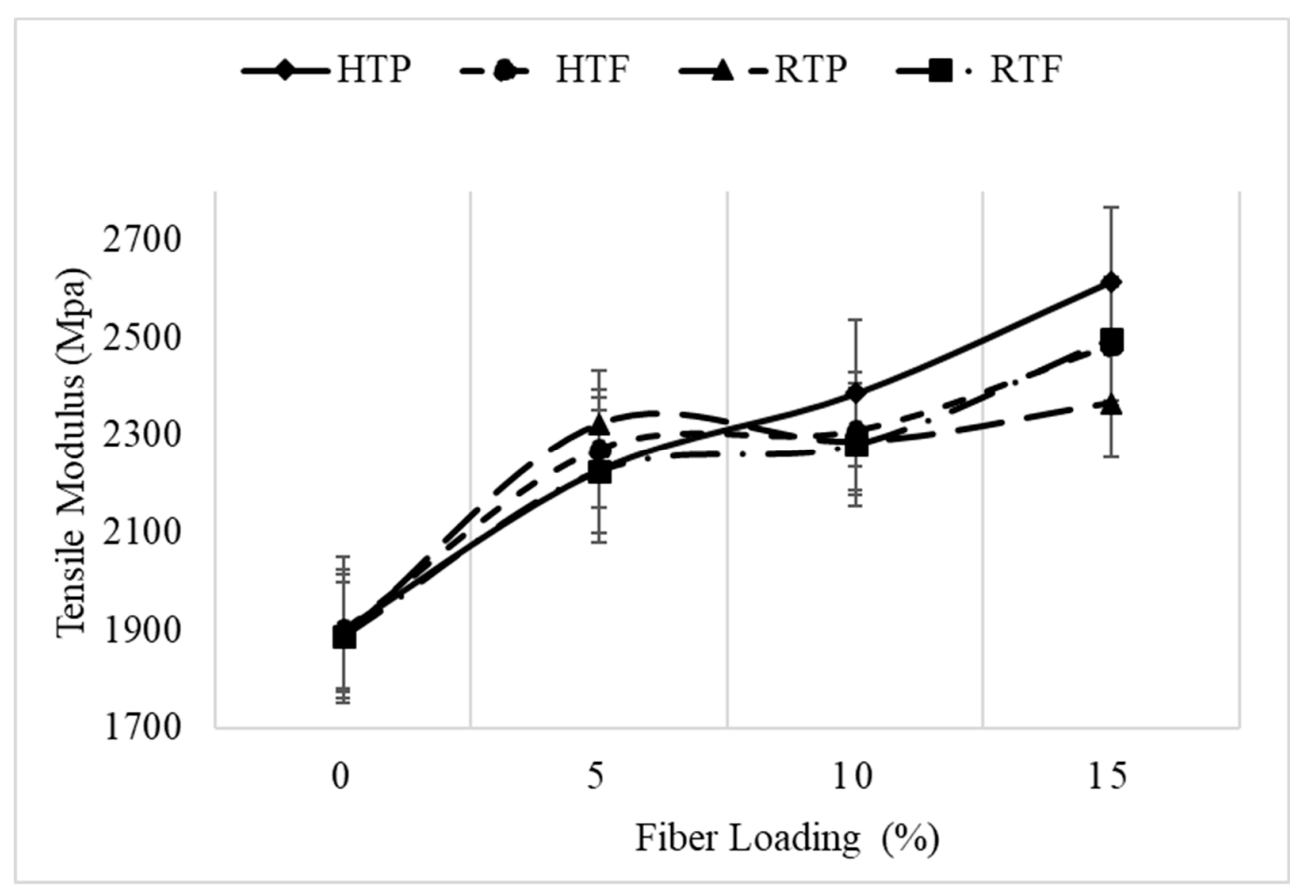

Figure 6. Tensile moduli of virgin and recycled PP composites.

\subsection{Morphological Analysis}

Figure 7 shows that the untreated fibers accumulated on the surface of the composite specimens, which indicates the incompatibility between the fiber and the polymer. The treated fibers, on the other 
hand, only slightly accumulated on the surface of the composite specimens, which indicates that the alkali treatment enhanced the compatibility between the fiber and the polymer.

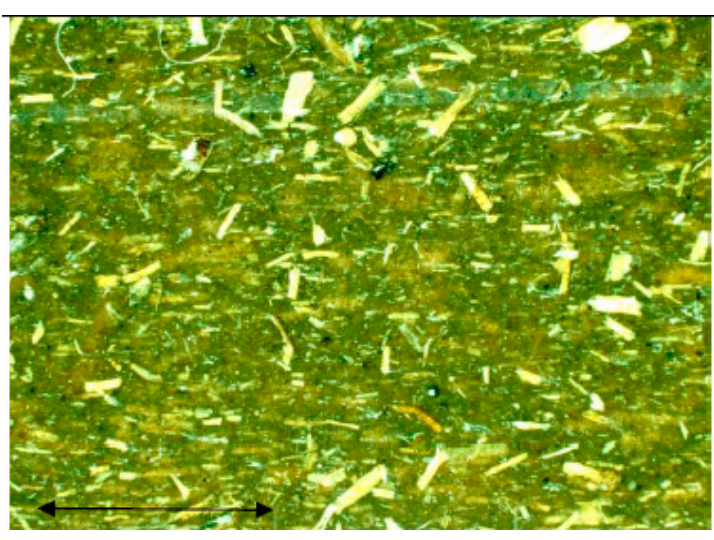

(a)

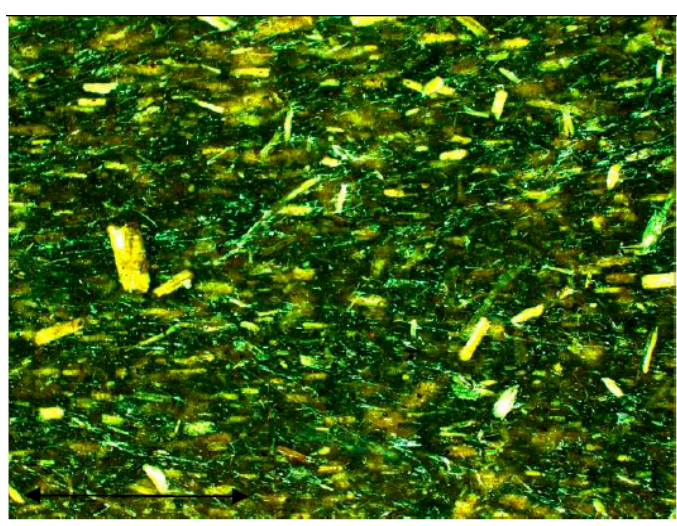

(c)

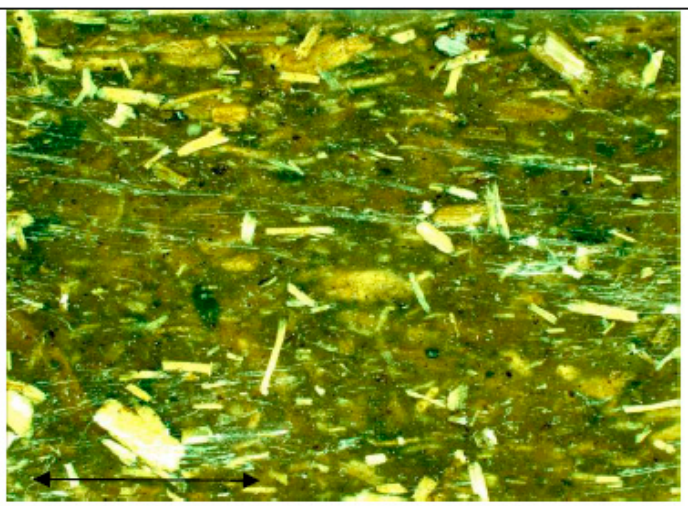

(b)

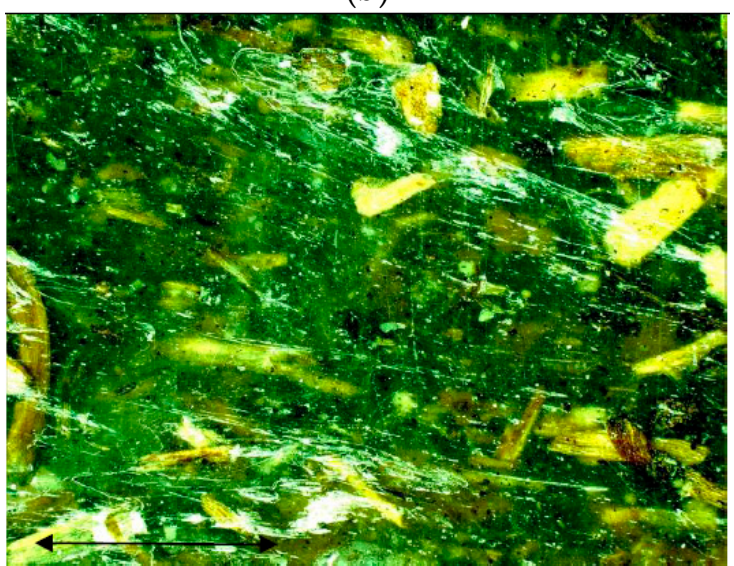

(d)

Figure 7. Surface microscopy images of HPP composite with $15 \%$ loading of date palm fiber (DPF). (a) Untreated powder; (b) untreated fiber; (c) treated powder; (d) treated fiber.

Similarly, the fracture cross-section SEM images of the of the untreated fibers, as shown in Figure 8, show extensive fiber pull out and a rough surface, which explains the reduction in tensile strength due to fiber loading [7]. In addition, irregular fiber shapes in the matrix indicate improper mixing. Proper mixing plays a vital role in improving the adhesion between the fiber and the polymeric matrix [15]. The SEM images of the composites reinforced with the treated fibers exhibit smoother fracture surfaces with minimal fiber pullout compared with the untreated fibers owing to the enhancement in interfacial adhesion [7]. 


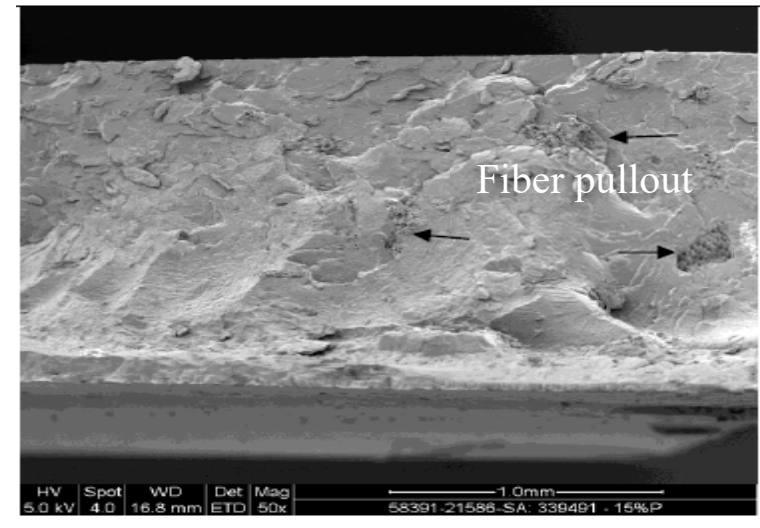

(a)

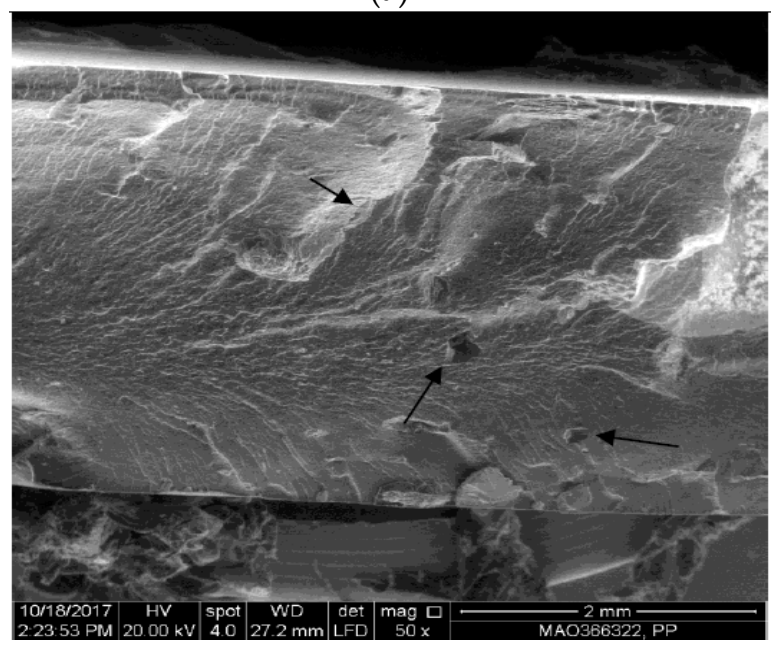

(c)

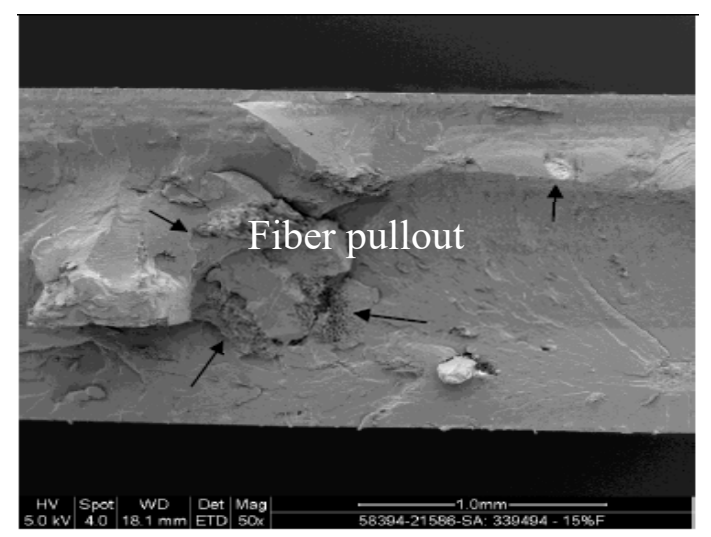

(b)

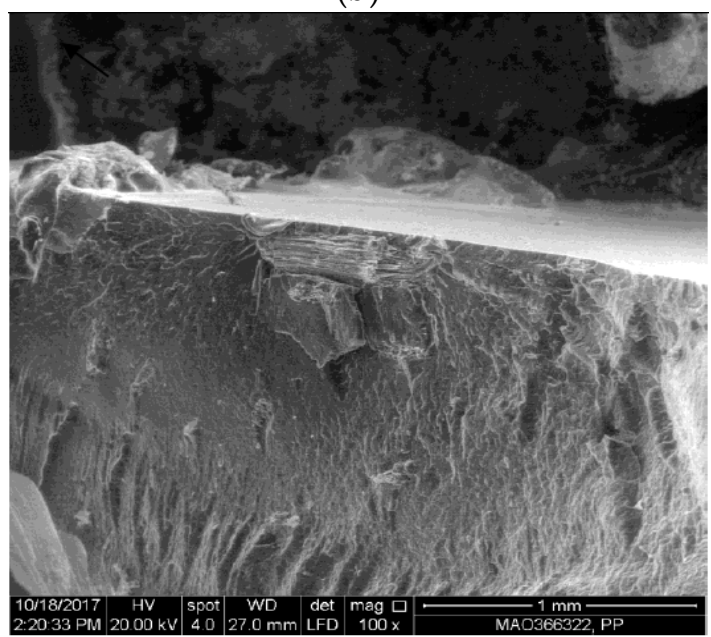

(d)

Figure 8. SEM images of fractured surfaces of HPP composite with 15\% loading of DPF. (a) Untreated powder; (b) untreated fiber; (c) treated powder; (d) treated fiber.

\subsection{Attenuated Total Reflection (ATR)-FTIR Analysis}

ATR analysis is a FTIR spectroscopy sampling technique that can show the differences in the chemical structures of the treated and untreated fibers. Figure 9 displays the ATR-FTIR spectra of the raw and alkali-treated DPFs. Table 3 shows the different bands and their corresponding functional groups. The wide absorption band at $3329 \mathrm{~cm}^{-1}$ is due to $\mathrm{O}-\mathrm{H}$ stretching and can be seen in the spectra of both the treated and untreated fibers with a slight difference. The peak at $2921 \mathrm{~cm}^{-1}$ is attributed to the aliphatic $\mathrm{C}-\mathrm{H}$ stretching vibration, while the peak at $1724 \mathrm{~cm}^{-1}$ is associated with the carbonyl group $(\mathrm{C}=\mathrm{O})$ stretching vibration. Nonetheless, the spectrum of the treated fibers shows a reduction in the absorption of the carbonyl group due to the removal of hemicellulose after the $\mathrm{NaOH}$ treatment. The peak at $1238 \mathrm{~cm}^{-1}$ is associated with the bending vibration of the $\mathrm{CH}_{3}$ group. These findings are similar to the FTIR spectroscopy results of coir and date palm fibers [16].

Table 3. Infrared transmittance bands $\left(\mathrm{cm}^{-1}\right)$ of raw and alkali-treated DPFs.

\begin{tabular}{ccc}
\hline Bond Type & Raw Fiber & Treated 5\% Alkaline \\
\hline -OH stretching & 3329 & 3331 \\
C = H vibration & 2921 & 2918 \\
C = O stretching & 1724 & - \\
C = C stretching & 1595 & 1592 \\
C-H bending & 1238 & 1234 \\
C-C stretching & 1029 & 1028 \\
\hline
\end{tabular}




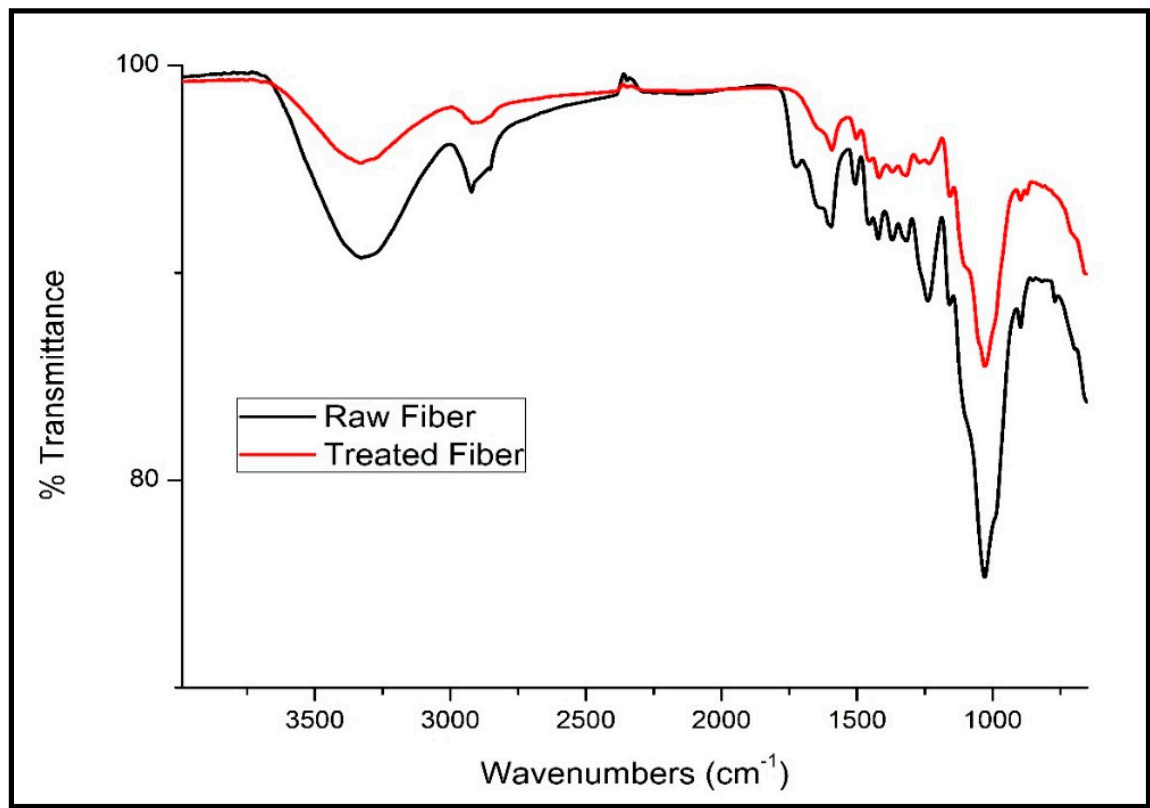

Figure 9. Attenuated total reflectance (ATR)-FTIR spectra of raw and alkali-treated fibers.

\subsection{Differential Scanning Calorimetry (DSC)}

\subsubsection{Non-Treated Fiber/PPH Composite}

Table 4 shows that addition of untreated fibers in the homo polypropylene matrix has no significant impact on the crystallinity index. It may be due to the fact that impurities present in the surface of the untreated fiber reduces the contact area with the polymeric matrix [17].

Table 4. Crystallinity index of non-treated fibers/PPH composites.

\begin{tabular}{ccccc}
\hline Sample & $\mathbf{T m}\left({ }^{\circ} \mathbf{C}\right)$ & $\mathbf{T c}\left({ }^{\circ} \mathbf{C}\right)$ & $\boldsymbol{\Delta H}_{\mathbf{m}}$ & Crystallinity $\%$ \\
\hline PPH Neat & 163.04 & 123.33 & 90.36 & $43.7 \%$ \\
HNTP 5\% & 163.37 & 122.39 & 84.13 & $42.8 \%$ \\
HNTP 10\% & 163.36 & 122.19 & 80.51 & $43.2 \%$ \\
HNTP 15\% & 161.71 & 122.61 & 70.91 & $40.3 \%$ \\
HNTF 5\% & 163.07 & 122.62 & 82.44 & $41.9 \%$ \\
HNTF 10\% & 162.53 & 122.51 & 79.83 & $42.9 \%$ \\
HNTF 15\% & 161.59 & 122.46 & 76.09 & $43.2 \%$ \\
\hline
\end{tabular}

\subsubsection{Treated Fiber/PPH Composite}

Table 5 shows the crystallinity index of treated fibers/PPH composites. DSC results show that the crystallinity index has been increased significantly after the alkali treatment and this can be explained by the dissolution of hemicellulose, which consequently promoted the breakdown of the fiber into micro fibrils. Due to this phenomenon the effective contact surface has improved. Furthermore, the crystalline cellulosic chains rearrange themselves, thereby enhancing the crystallinity index [18]. In addition to that, fibrillation and disappearance of amorphous hemicellulose improved the aspect ratio of the date palm fiber. 
Table 5. Crystallinity index of treated fibers/PPH composites.

\begin{tabular}{ccccc}
\hline Sample & Tm $\left({ }^{\circ} \mathbf{C}\right)$ & Tc $\left({ }^{\circ} \mathbf{C}\right)$ & $\boldsymbol{\Delta H}_{\mathbf{m}}$ & Crystallinity $\%$ \\
\hline PPH Neat & 163.04 & 123.33 & 90.36 & $43.7 \%$ \\
HTP 5\% & 162.67 & 123.89 & 89.47 & $45.5 \%$ \\
HTP 10\% & 163.4 & 123.63 & 81.46 & $43.7 \%$ \\
HTP 15\% & 162.11 & 123.74 & 76.54 & $43.5 \%$ \\
HTF 5\% & 162.67 & 123.22 & 97.1 & $49.4 \%$ \\
HTF 10\% & 162.25 & 122.96 & 89.09 & $47.8 \%$ \\
HTF 15\% & 163.16 & 123.66 & 80.54 & $45.8 \%$ \\
\hline
\end{tabular}

\subsubsection{Treated Fiber/Recycled PPH Composite}

Table 6 shows the crystallinity index of treated fibers/PPH recycled matrix composites. DSC results show that the crystallinity index has been increased in a way similar to the prime matrix. Thus, there is no significant difference between the recycled and prime matrices' interactions with the treated fibers.

Table 6. Crystallinity index of treated fibers/PPH recycled matrix composites.

\begin{tabular}{ccccc}
\hline Sample & Tm $\left({ }^{\circ} \mathbf{C}\right)$ & Tc $\left({ }^{\circ} \mathbf{C}\right)$ & $\Delta \mathbf{H}_{\mathbf{m}}$ & Crystallinity $\%$ \\
\hline Recycled & 162.78 & 123.51 & 83.78 & $40.5 \%$ \\
PPH Neat & 162.43 & 123.8 & 72.79 & $37.0 \%$ \\
RTP 5\% & 162.98 & 123.73 & 77.98 & $41.9 \%$ \\
RTP 10\% & 162 & 123.85 & 80.23 & $45.6 \%$ \\
RTP 15\% & 162.32 & 123.64 & 79.93 & $40.6 \%$ \\
RTF 5\% & 161.57 & 123.73 & 81.47 & $43.7 \%$ \\
RTF 10\% & 162.36 & 124.04 & 81.43 & $46.3 \%$ \\
RTF 15\% & & & & \\
\hline
\end{tabular}

\subsubsection{Treated Fiber/ICP Composite}

Table 7 shows the crystallinity index of treated fiber/ICP composites. DSC results show that addition of treated fibers to the ICP matrix has insignificant impact on the crystallinity index. These results can validate the tensile modulus results.

Table 7. Crystallinity index of treated fibers/ICP matrix composites.

\begin{tabular}{ccccc}
\hline Sample & $\operatorname{Tm}\left({ }^{\circ} \mathbf{C}\right)$ & $\mathbf{T c}\left({ }^{\circ} \mathbf{C}\right)$ & $\Delta \mathbf{H}_{\mathbf{m}}$ & Crystallinity $\%$ \\
\hline ICP Neat & 161.98 & 123.12 & 83.95 & $40.6 \%$ \\
CTP 5\% & 161.89 & 123.41 & 74.81 & $38.0 \%$ \\
CTP 10\% & 161.9 & 124.09 & 75.08 & $40.3 \%$ \\
CTP 15\% & 162.47 & 124.19 & 72.97 & $41.5 \%$ \\
CTF 5\% & 161.26 & 122.91 & 77.53 & $39.4 \%$ \\
CTF 10\% & 162.11 & 122.78 & 73.08 & $39.2 \%$ \\
CTF 15\% & 161.78 & 122.98 & 71.39 & $40.6 \%$ \\
\hline
\end{tabular}

\subsection{Thermogravimetric Analysis (TGA)}

TGA analysis was carried out to investigate the thermal stability of untreated DPF/PPH, treated $\mathrm{DPF} / \mathrm{PPH}$, treated DPF/recycled PPH, and treated DPF/ICP composites at different DPF wt $\%$ and lengths.

\subsubsection{Non-Treated Fiber/PPH Composite}

From the thermogram shown in Figure 10, it is clear that PPH samples exhibited major degradation shifts (around $400^{\circ} \mathrm{C}$ ) compared to other composite samples. Addition of fibers in the PPH matrix has declined the thermal stability of the composites. It can be attributed to the degradation of natural chemicals, such as cellulose, hemicellulose, and lignin present in the date palm fiber. The initial 
degradation around $100-150^{\circ} \mathrm{C}$ was associated with the evaporation of water molecules [19]. Then, the natural chemicals, such as hemicellulose and cellulose, were degraded at 290 and $360{ }^{\circ} \mathrm{C}$, respectively [20]. The major degradation occurs in between 350 and $450{ }^{\circ} \mathrm{C}$ for all the composite samples with minimal deviations. The polypropylene matrix degraded around $400{ }^{\circ} \mathrm{C}$. The sample at $300^{\circ} \mathrm{C}$ has lost $4 \%$ of its weight due to the degradation of hemicellulose and other components, which degrade before $300{ }^{\circ} \mathrm{C}$.

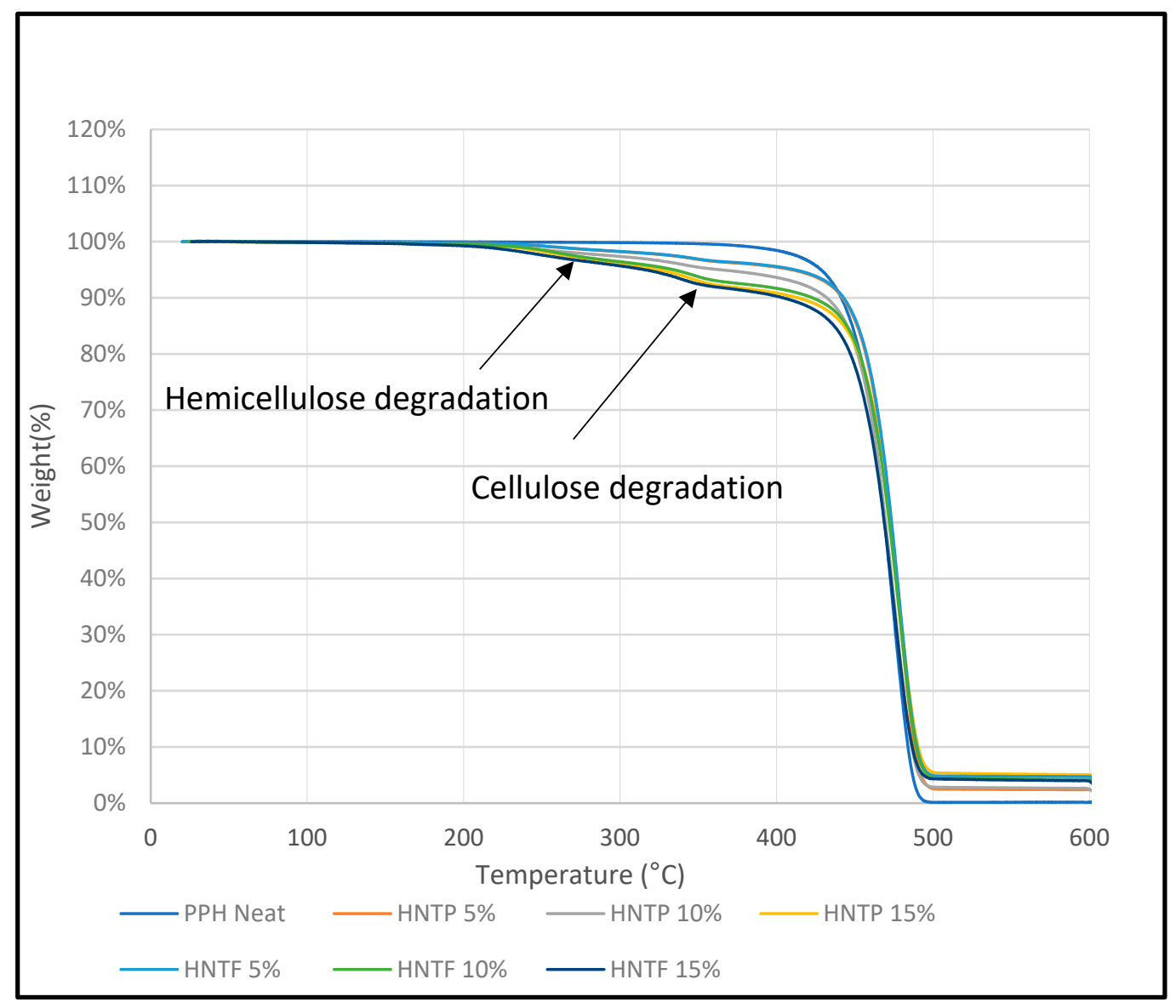

Figure 10. TGA of homo polypropylene-non-treated fiber composites.

\subsubsection{Treated Fiber/PPH Composite}

Figure 11 shows that addition of treated fibers into the PPH matrix has decreased the thermal stability of the composite, but it is clear that the treatment mitigated the degradation by hemicellulose removal, which usually degrades at around $290^{\circ} \mathrm{C}$. Furthermore, it is good to know that the reason that makes the composite degradation start before $300^{\circ} \mathrm{C}$ is not only the hemicellulose, but also the lignin, which decomposes slower, and over a broader temperature range $\left(200-500^{\circ} \mathrm{C}\right)$ [21] than cellulose and the hemicellulose components. At $300{ }^{\circ} \mathrm{C}$, all the treated fiber-reinforced composite samples exhibited only $2 \%$ weight loss. On the other hand, untreated DPF-reinforced homo polypropylene composites showed $4 \%$ weight loss at $300{ }^{\circ} \mathrm{C}$. It has corroborated the fact that treated fiber enhanced the thermal stability of the composites. 


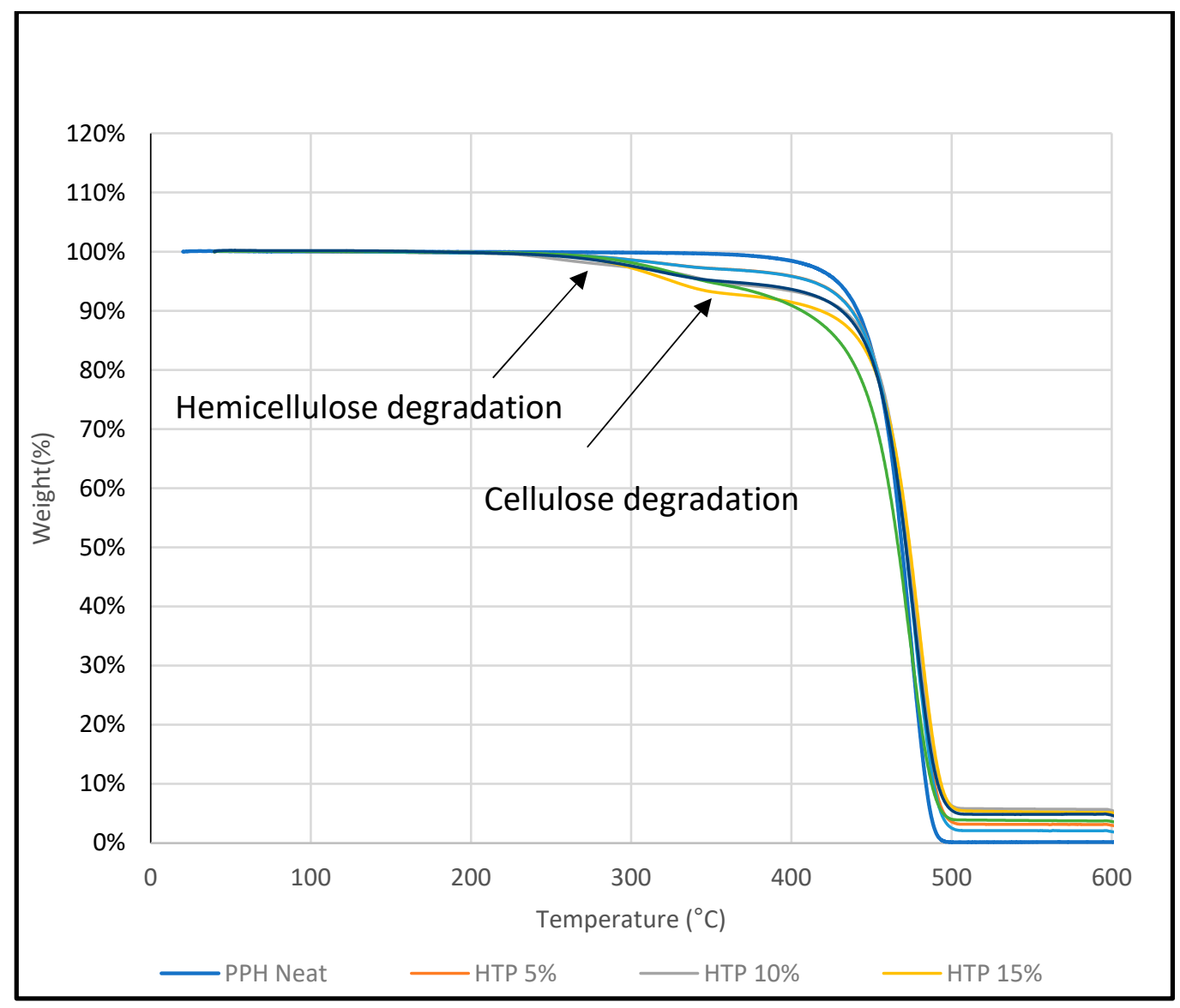

Figure 11. TGA of homo polypropylene-treated fiber composites.

\subsubsection{Treated Fiber/Recycled PPH Composite}

Figure 12 shows that the thermal degradation profile and thermal stability of recycled PPH /DPF composite is almost similar to PPH/DPF composites, as shown in Figure 12. In particular, the major degradation temperature was found at $420-450{ }^{\circ} \mathrm{C}$ for both recycled PPH/DPF composites and $\mathrm{PPH} / \mathrm{DPF}$ composites, irrespective of the wt $\%$ of fiber and length. Hence, using recycled PPH with the treated fibers instead of prime matrix did not change the thermal stability of the composite, which proves that recycling did not affect the thermal stability of the homo polypropylene matrix [6]. Thus, recycled PPH can be utilized as an alternative to the prime material with DPF. 


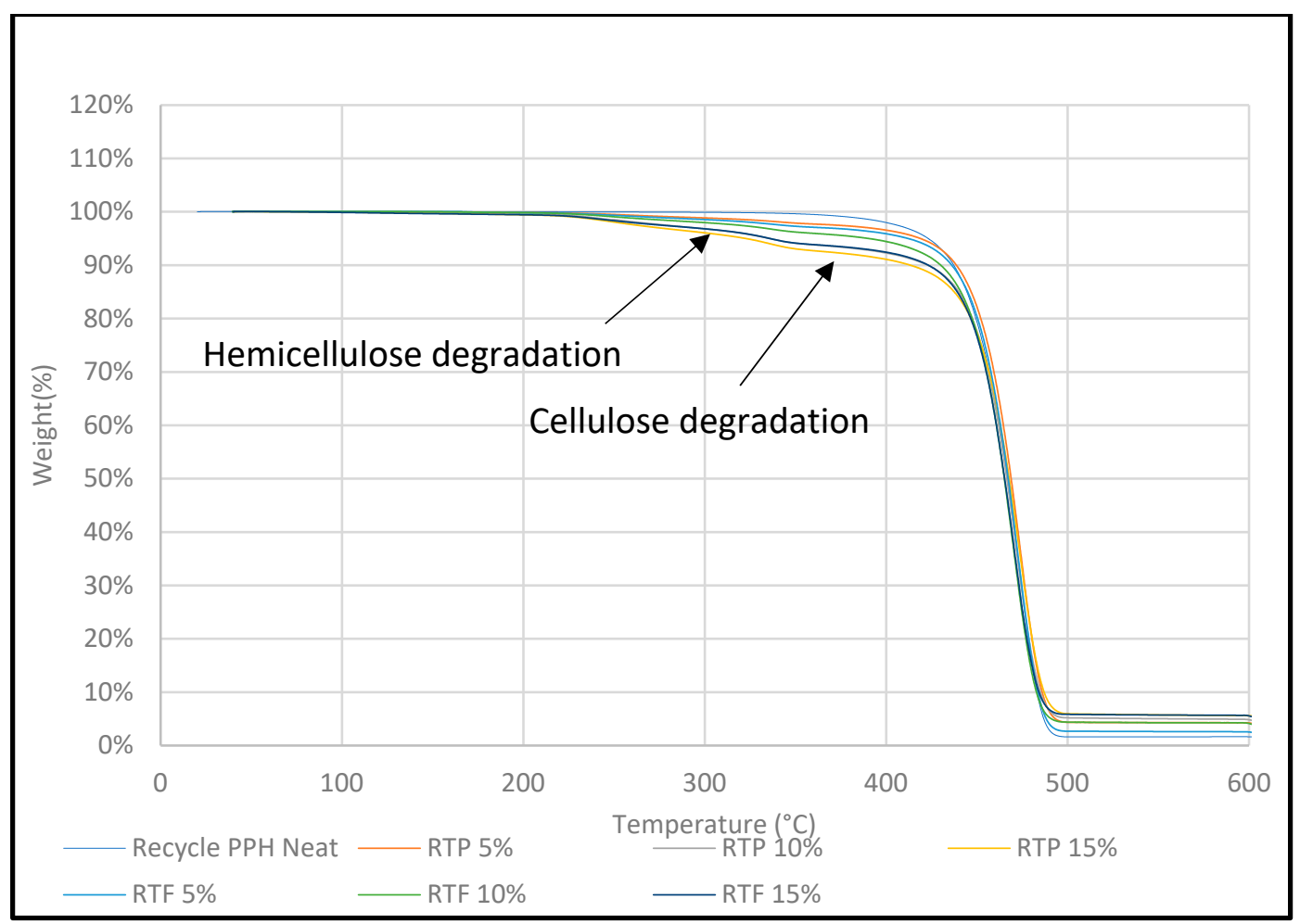

Figure 12. TGA of recycled homo polypropylene-treated fiber composites.

\subsubsection{Treated Fiber/ICP Composite}

Figure 13 shows that neat ICP exhibited higher thermal stability compared to treated fiber-reinforced ICP composites. Nonetheless, the major degradation temperature was observed in between 420 and $450^{\circ} \mathrm{C}$ for all the treated DPF/ICP composite samples. Thus, impact copolymer matrix with the treated fibers showed similar thermal stability and degradation curves compared to homo or copolymer with DPF. 


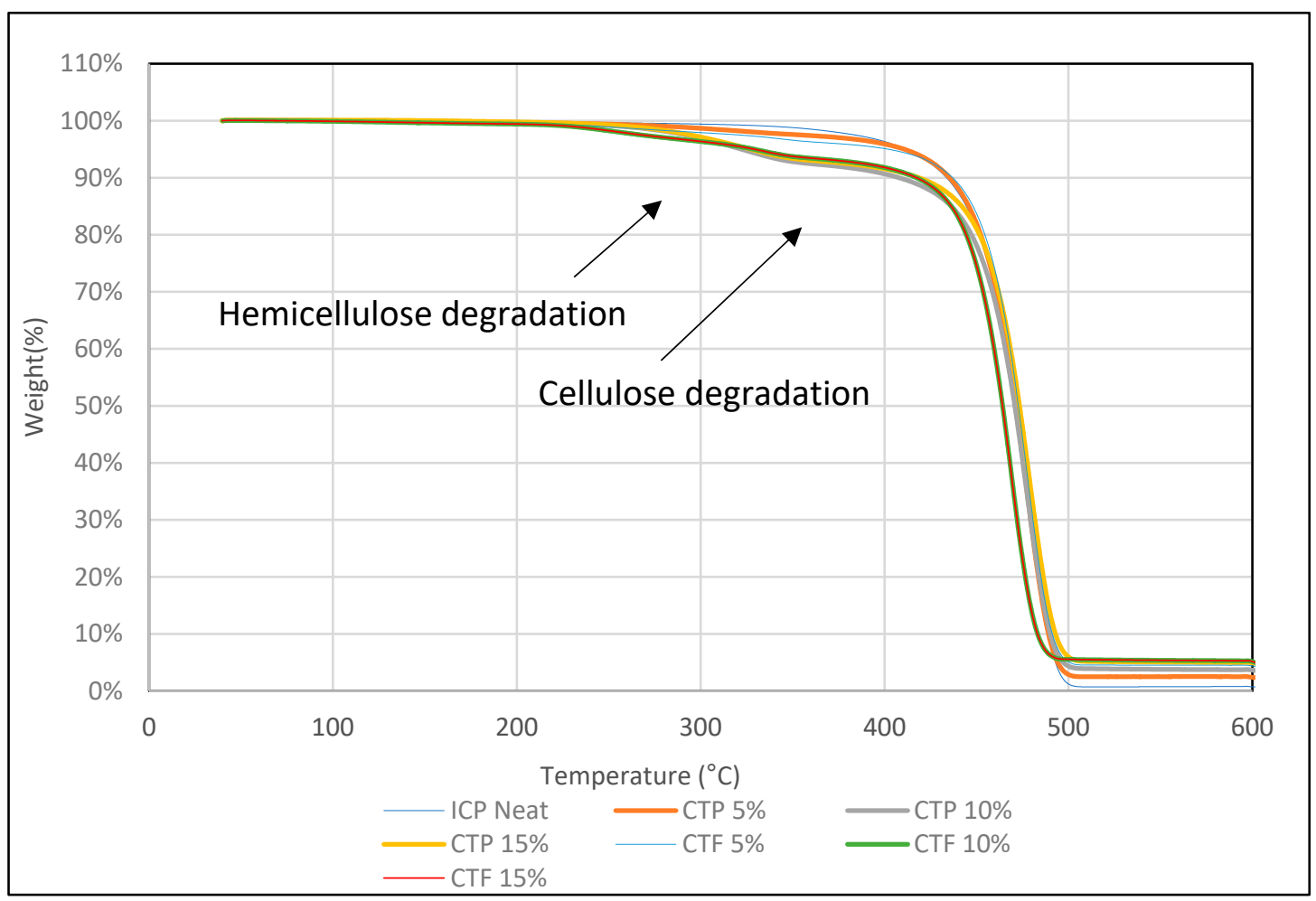

Figure 13. TGA of ICP-treated fiber composites.

\subsubsection{Matrices' Comparison}

Figure 14 shows the thermogram of different PP matrices. It is clearly understood that PPH has shown the better thermal stability, followed by recycled PPH and ICP. However, no significant difference in degradation temperature was observed. $\mathrm{PPH}$, recycled PPH, and ICP follows a similar degradation profile with slight deviations. The major degradation temperature is in between 420 and $450^{\circ} \mathrm{C}$ for all the polypropylene samples. The final degradation temperature was found beyond $450{ }^{\circ} \mathrm{C}$. However, beyond $500{ }^{\circ} \mathrm{C}$, all the polypropylene samples were degraded completely.

Derivative thermogravimetric (DTG) analysis was carried out to investigate the thermal stability of various DPF/PP composites with different DPF sizes and loadings.

Figures 15 and 16 show that the HPP degradation peak (around $400{ }^{\circ} \mathrm{C}$ ) shifted toward higher temperatures after the addition of DPFs. In general, DPF/polymer composites exhibit three stages of degradation. The initial degradation around $100-150{ }^{\circ} \mathrm{C}$ is associated with the evaporation of water molecules [19]. This stage was not observed, which indicates enough drying. However, the other two degradation stages were observed. First, the natural components, such as hemicellulose and cellulose, degraded at 290 and $360^{\circ} \mathrm{C}$, respectively [20]. Then, a major degradation occurred between 350 and $450{ }^{\circ} \mathrm{C}$ for all the composite samples with minimal deviations. The polypropylene matrix degraded around $400{ }^{\circ} \mathrm{C}$. Similar results were observed from the DTG curves of the composites for both the fiber sizes. 


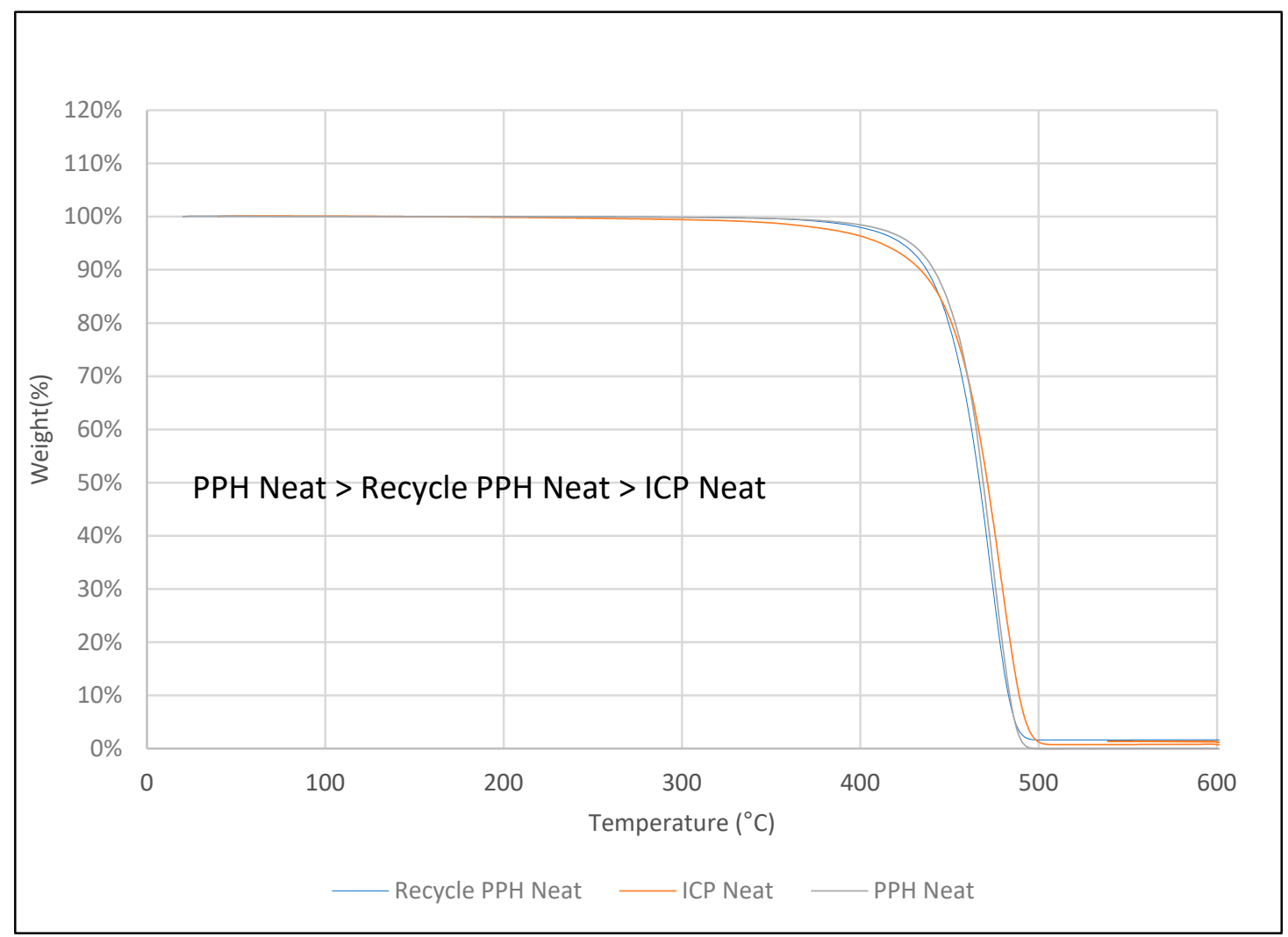

Figure 14. TGA of different PP matrices.

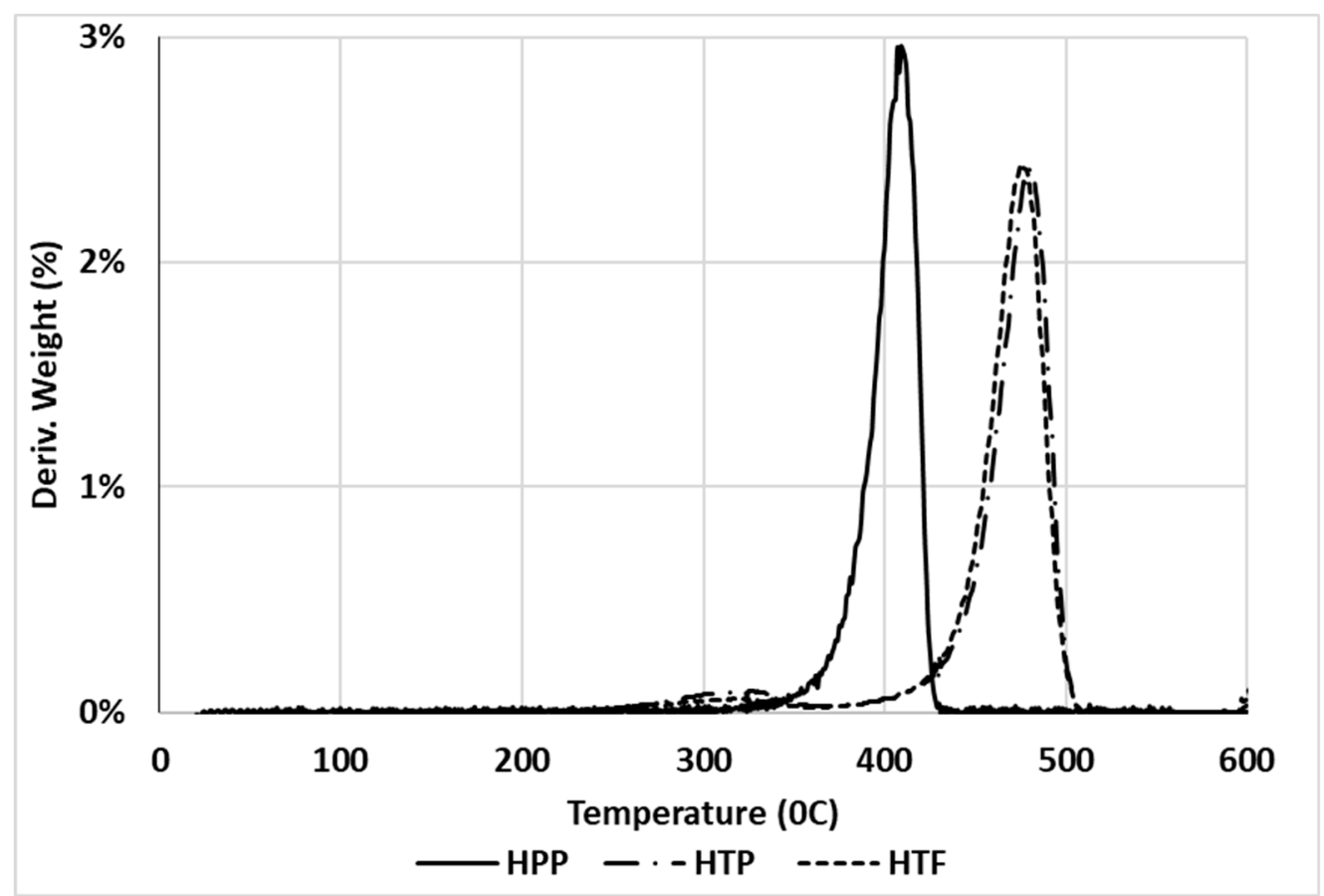

Figure 15. Derivative thermogravimetric (DTG) curves of treated DPF/HPP composites. 


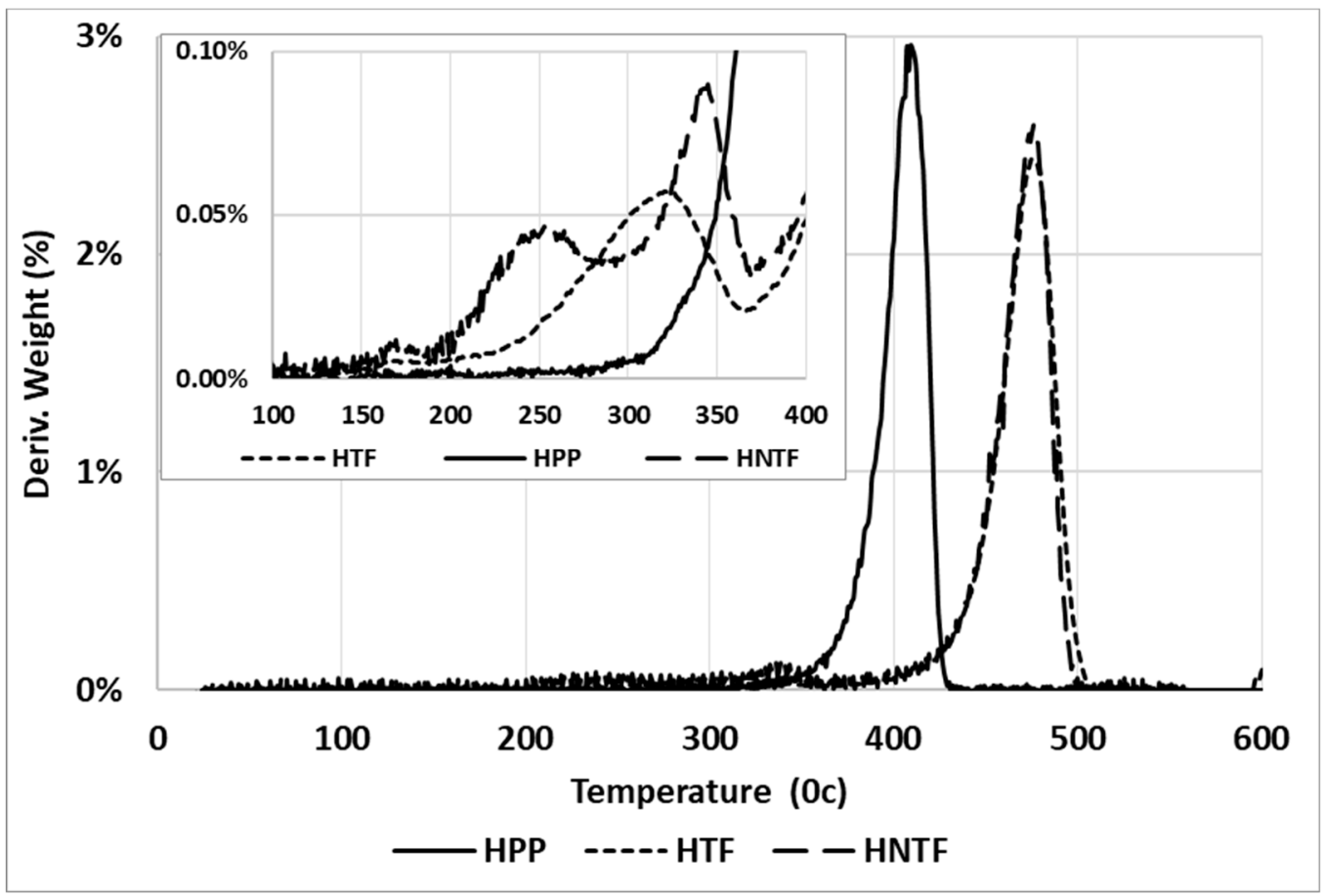

Figure 16. DTG curves of treated and untreated DPF/HPP composites.

It is evident that the treatment mitigated degradation through hemicellulose removal, which usually degrades at around $290^{\circ} \mathrm{C}$. In addition, the composite degradation started before $300{ }^{\circ} \mathrm{C}$, which is because of not only hemicellulose, but also lignin that decomposes slowly and over a broader temperature range $\left(200-500^{\circ} \mathrm{C}\right)$ [21] compared with the cellulose and hemicellulose components. At around $300{ }^{\circ} \mathrm{C}$, the treated fiber-reinforced composite samples exhibited only $2 \%$ weight loss, while the untreated DPF-reinforced composites showed $4 \%$ weight loss; this indicates that the treated fibers enhanced the thermal stability of the composites. Similar results were observed for the rPP and ICP composites.

Hence, the use of rPP with the treated fibers instead of virgin HPP did not change the thermal stability of the composites, which proves that recycling does not affect the thermal stability of the HPP matrix. Thus, rPP can be used as an alternative to the virgin polymer with DPFs.

\section{Conclusions}

The effect of different DPF sizes on various types of polypropylene matrices was investigated. Based on the results, the following conclusions were drawn:

- The alkali treatment of DPFs improved the tensile properties of the homo-polypropylene, co-polypropylene, and rPP composites. An increase in fiber loading decreased the tensile strength and increased the modulus.

- The microscopy images showed that the untreated fibers accumulated on the surface of the composite specimens, which indicates the incompatibility between the fiber and the polymer matrix. However, the alkali treatment of fiber improved the adhesion between the fibers and the matrices.

- The ATR-FTIR analysis results indicated that after the chemical treatment, the functional groups present in the DPFs strongly interacted with the polypropylene matrix.

- The DSC results further proved that the alkali treatment improved the crystallinity index of the DPF/PP composites.

- The TGA results showed that the thermal stabilities of the treated fiber-reinforced rPP and ICP composites are comparable to that of the DPF/homo-polypropylene composite. 
Thus, recycled polypropylene can be used as an alternative to homo-polypropylene with DPFs.

Author Contributions: M.S.A.-O. performed the experiment and wrote the manuscript with input from O.Y.A.; M.M.A. and A.A. analyzed the data; J.N. corrected the manuscript; M.J. supported for materials and experiments. All authors have read and agreed to the published version of the manuscript.

Funding: This research was funded by the Deanship of Scientific Research at King Saud University, grant number RG-133 and "The APC was funded by Research Group No. RG-133".

Acknowledgments: The authors extend their appreciation to the Deanship of Scientific Research at King Saud University for funding this work through research group No. RG-133.

Conflicts of Interest: The authors declare no conflict of interest.

\section{References}

1. Kim, S.J.; Moon, J.B.; Kim, G.H.; Ha, C.S. Mechanical properties of polypropylene/natural fiber composites: Comparison of wood fiber and cotton fiber. Polym. Test. 2008, 27, 801-806. [CrossRef]

2. Jesuarockiam, N.; Jawaid, M.; Zainudin, E.S.; Thariq Hameed Sultan, M.; Yahaya, R. Enhanced thermal and dynamic mechanical properties of synthetic/natural hybrid composites with graphene nanoplateletes. Polymers 2019, 11, 1085. [CrossRef] [PubMed]

3. Alotaibi, M.D.; Alshammari, B.A.; Saba, N.; Alothman, O.Y.; Sanjay, M.R.; Almutairi, Z.; Jawaid, M. Characterization of natural fiber obtained from different parts of date palm tree (Phoenix dactylifera L.). Int. J. Biol. Macromol. 2019, 135, 69-76. [CrossRef] [PubMed]

4. Saba, N.; Alothman, O.Y.; Almutairi, Z.; Jawaid, M.; Ghori, W.J. Date palm reinforced epoxy composites: Tensile, impact and morphological properties. J. Mater. Res. Technol. 2019, 8, 3959-3969. [CrossRef]

5. Al-Sulaiman, F.A. Mechanical properties of date palm fiber reinforced composites. Appl. Compos. Mater. 2002, 9, 369-377. [CrossRef]

6. Puglia, D.; Petrucci, R.; Fortunati, E.; Luzi, F.; Kenny, J.M.; Torre, L. Revalorisation of posidoniaoceanica as reinforcement in polyethylene/maleic anhydride grafted polyethylene composites. J. Renew. Mater. 2014, 2, 66-76. [CrossRef]

7. Abu-Sharkh, B.F.; Kahraman, R.; Abbasi, S.H.; Hussein, I.A. Effect of epolene E-43 as a compatibilizer on the mechanical properties of palm fiber-poly (propylene) composites. J. Appl. Polym. Sci. 2004, 92, 2581-2592. [CrossRef]

8. Alawar, A.; Hamed, A.M.; Al-Kaabi, K. Characterization of treated date palm tree fiber as composite reinforcement. Compos. Part B 2009, 40, 601-606. [CrossRef]

9. Abdal-Hay, A.; Suardana, N.P.G.; Choi, K.S.; Lim, J.K. Effect of diameters and alkali treatment on the tensile properties of date palm fiber reinforced epoxy composites. Int. J. Precis. Eng. Manuf. 2012, 13, 1199-1206. [CrossRef]

10. Adel, W.M.; Kamal, H.; El-Soualey, D. Experimental determination of some design properties of viscoelastic solid propellant using uniaxial tensile test. In Proceedings of the International Conference on Aerospace Sciences and Aviation Technology, Cairo, Egypt, 24-26 May 2011; Volume 14, pp. 1-11, No. AEROSPACE SCIENCES \& AVIATION TECHNOLOGY, ASAT-14.

11. Mahmoudi, N.; Hebbar, N. Study of mechanical properties of a composite-based plant fibre of the palm and thermoplastic matrices (PP). J. Compos. Mater. 2014, 48, 291-299. [CrossRef]

12. Oushabi, A.; Sair, S.; Hassani, F.O.; Abboud, Y.; Tanane, O.; El Bouari, A. The effect of alkali treatment on mechanical, morphological and thermal properties of date palm fibers (DPFs): Study of the interface of DPF-Polyurethane composite. S. Afr. J. Chem. Eng. 2017, 23, 116-123. [CrossRef]

13. Hodkhasa, S. Wave Propagation and Damage Characterization in Natural Fiber Hemp and LLDPE Composite. Master's Thesis, Texas A\&M University, College Station, TX, USA, May 2013.

14. Thomas, G.P. Recycling of Polypropylene (PP). Clean Tech. 2012, 101, 25.

15. Rozman, H.D.; Peng, G.B.; Mohd. Ishak, Z.A. The effect of compounding techniques on the mechanical properties of oil palm empty fruit bunch-polypropylene composites. J. Appl. Polym. Sci. 1998, 70, 2647-2655. [CrossRef]

16. Wong, K.J.; Yousif, B.F.; Low, K.O. The effects of alkali treatment on the interfacial adhesion of bamboo fibres. Proc. Inst. Mech. Eng. Part L 2010, 224, 139-148. [CrossRef] 
17. El-Abbassi, F.E.; Assarar, M.; Ayad, R.; Lamdouar, N. Effect of alkali treatment on Alfa fibre as reinforcement for polypropylene based eco-composites: Mechanical behaviour and water ageing. Compos. Struct. 2015, 133, 451-457. [CrossRef]

18. Smitthipong, W.; Chollakup, R.; Nardin, M. Bio-Based Composites for High-Performance Materials: From Strategy to Industrial Application; CRC Press: Boca Raton, FL, USA, 2014.

19. Jonoobi, M.; Harun, J.; Mishra, M.; Oksman, K. Chemical composition, crystallinity and thermal degradation of bleached and unbleached kenaf bast (Hibiscus cannabinus) pulp and nanofiber. BioResources 2009, 4, 626-639.

20. Sinha, E.; Rout, S.K. Influence of fibre-surface treatment on structural, thermal and mechanical properties of jute fibre and its composite. Bull. Mater. Sci. 2009, 32, 65. [CrossRef]

21. Ibrahim, M.N.M.; Zakaria, N.; Sipaut, C.S.; Sulaiman, O.; Hashim, R. Chemical and thermal properties of lignins from oil palm biomass as a substitute for phenol in a phenol formaldehyde resin production. Carbohydr. Polym. 2011, 86, 112-119. [CrossRef]

(C) 2020 by the authors. Licensee MDPI, Basel, Switzerland. This article is an open access article distributed under the terms and conditions of the Creative Commons Attribution (CC BY) license (http://creativecommons.org/licenses/by/4.0/). 